\title{
EFFECTS OF ENDOTHELIAL CELLS ON HUMAN MESENCHYMAL STEM CELL ACTIVITY IN A THREE-DIMENSIONAL IN VITRO MODEL
}

\author{
F. A. Saleh ${ }^{1}$, M. Whyte ${ }^{2}$ and P. G. Genever ${ }^{1 *}$ \\ ${ }^{1}$ Biomedical Tissue Research, Department of Biology, University of York, York, UK \\ ${ }^{2}$ Smith \& Nephew Research Centre, York Science Park, York, UK
}

\begin{abstract}
An increasing body of data suggest that mesenchymal stem cells (MSCs) reside in a perivascular niche. To more closely mimic this in vivo microenvironment and for better understanding of its complexity, and the factors that regulate the MSC activity, human umbilical vein endothelial cells (HUVECs) were co-cultured with human bone marrow MSCs - using a novel three-dimensional (3D) spheroid co-culture system. Using confocal microscopy of fluorescently labelled cells, we observed HUVECs and MSCs to self-assemble and form organised structures with segregated cell-type partitioning. Under osteogenic conditions, the rate and extent of differentiation in MSC/ HUVEC spheroids was significantly elevated compared to 3D co-cultures of MSCs and human dermal fibroblast controls as shown by alkaline phosphatase staining. Conversely, HUVECs inhibited adipogenic differentiation and the proliferation of MSCs in 3D co-cultures indicating that HUVECs suppressed MSC cycling and selectively promoted osteogenic differentiation in $3 \mathrm{D}$. We have also shown that HUVECs enhanced activation of endogenous Wnt signalling and bone morphogenetic protein (BMP) signalling as shown by increased levels of active nuclear $\beta$-catenin and pSmad 1/5/8 immunopositivity respectively.

These data suggest strongly that endothelial cells regulate the MSC activity in simulated in vivo conditions, by maintaining quiescence and facilitating niche exit via osteogenic differentiation following appropriate cues. Our findings also underline the importance of 3D heterotypic cell-cell interactions in the regulation of MSC behaviour, suggesting that multicellular cocktails and/or 3D-based delivery strategies may be beneficial for bone repair.
\end{abstract}

Keywords: Mesenchymal stem cells, 3D models, endothelial cells, perivascular niche, osteogenesis.

*Address for correspondence:

Paul G. Genever

Biomedical Tissue Research

Department of Biology (Area 9)

University of York

York, YO10 5DD, UK

Telephone Number: +44 (0) 1904328649

FAX Number: +44 (0) 1904328659

E-mail: paul.genever@york.ac.uk

\section{Introduction}

Mesenchymal stem cells (MSCs) are multipotent adult cells that have the ability to self-renew and differentiate into multiple lineages, including osteogenic, adipogenic and chondrogenic. Their relative ease of isolation from many tissues and rapid expansion in culture, coupled with their high degree of plasticity, has made these cells an excellent candidate for a variety of research and therapeutic applications. Despite their apparent therapeutic potential, the clinical application of MSCs has been restricted due to our limited understanding of the factors that regulate their activity and our lack of knowledge of the complexity of the interplay between these cells and components of their immediate microenvironment or niche.

In vitro stem cell research is commonly carried out by culturing cells as monolayers using conventional tissue culture techniques. Growing cells on plastic dishes provides a simplified and adequate approach to studying the effects of isolated niche components on stem cell activity (such as proliferation and differentiation). However, it cannot effectively reflect the conditions experienced within a three-dimensional (3D) in vivo microenvironment (Lutolf et al., 2009). In an attempt to recreate this complex microenvironment and for a more comprehensive understanding of the conditions experienced by cells in the body, the use of 3D culture systems is gaining increasing attention. Data gained from $3 \mathrm{D}$ in vitro methods may help to bridge the gap between traditional 2D culture studies and in vivo pre-clinical animal models (Rangarajan et al., 2004; Griffith and Swartz, 2006; Yamada and Cukierman, 2007; Pampaloni et al., 2007; Hutmacher, 2010). Significant alterations in cell behaviour have been identified, when they are grown in $3 \mathrm{D}$ compared to $2 \mathrm{D}$ conditions; including changes in cell morphology (Cukierman et al., 2001), differentiation capacity (Arufe et al., 2009; Wang et al., 2009b), replicative ability (Grayson et al., 2006), cell signalling (Cukierman et al., 2002; Green and Yamada, 2007 ) as well as significant increases in their therapeutic potential (Tapp et al., 2008; Wang et al., 2009a; Dittmer et al., 2009; Bartosh et al., 2010; Frith et al., 2010). For example, we have previously shown that MSCs grown in dynamic 3D culture conditions can promote osteogenic and adipogenic differentiation potential (Frith et al., 2010). This dramatic change in cell activity is due to many external cues from different elements, including those that arise from extracellular matrix (ECM) components, mechanical stimulation, oxygen concentration, nutrient diffusion and soluble regulators from neighbouring cells - all of which contribute to the structure and function of the niche (Lutolf et al., 2009). To better mimic the in vivo 
settings, in this study we moved from a 2D monoculture to a $3 \mathrm{D}$ co-culture system to allow the analysis of heterotypic cell-cell interactions.

There is increasing evidence suggesting that MSCs reside in a perivascular niche, with more reports suggesting that MSCs are closely related to pericytes (Shi and Gronthos, 2003; Crisan et al., 2008a; da Silva et al., 2008; Castrechini et al., 2010). We have previously shown that endothelial cell-conditioned medium significantly affects MSC behaviour in 2D cultures (Saleh et al., 2011). For these reasons, this study has focused on physical interactions between MSCs and a main vascular cell type; endothelial cells using a 3D in vitro spheroid model. We hypothesised that the signals originating from endothelial cells in the MSC niche will influence MSC behaviour and cell fate decisions and may provide cues that regulate the maintenance and differentiation of MSCs in a 3D context. We confirmed that MSCs and endothelial cells self-assembled in 3D. The presence of endothelial cells significantly affected MSC proliferation and osteo/ adipogenic differentiation and enhanced Wnt/BMP signalling compared to a fibroblast control cell type. The model developed may provide a more appropriate culture system to study the effects of microenvironmental elements on MSC behaviour and other stem cell types and inform on appropriate cell delivery protocols to maximise clinical benefit in MSC-based therapies.

\section{Materials and Methods}

Tissue culture plasticware were purchased from Corning (Artington, UK) and all tissue culture media and supplements were obtained from Invitrogen (Paisley, UK) unless otherwise stated. Cells were cultured at $37^{\circ} \mathrm{C}$ in a humidified atmosphere with $5 \% \mathrm{CO}_{2}$.

\section{Cell culture}

Primary human MSCs were isolated from femoral heads of patients undergoing hip replacement operations following informed consent (Harrogate District Hospital, UK), as described previously (Etheridge et al., 2004), and showing positive expression of markers for culture-expanded MSCs: CD29, CD44, CD73, CD105, CD166, HLA I, whilst lacking expression of the endothelial marker CD31. The trabecular bone was collected from the femoral head, minced manually with sterile scissors, the supernatant collected and cells pelleted, followed by further rounds of rinsing with phosphate-buffered saline (PBS). The mononuclear cells were isolated with a density gradient (Ficoll-Paque, Amersham Biosciences, Amersham, UK) and maintained in T175 tissue culture flasks in Dulbecco's modified Eagle's medium (DMEM) containing $100 \mathrm{U} /$ $\mathrm{mL}$ penicillin $(\mathrm{P}), 100 \mu \mathrm{g} / \mathrm{mL}$ streptomycin $(\mathrm{S})$, and $15 \%$ batch tested foetal bovine serum (FBS). All experiments were performed with passage 2-5 MSCs. Results were obtained using three different donors with representative data shown.

Human Umbilical Vein Endothelial Cells (HUVEC) were obtained commercially from PromoCell $\mathrm{GmbH}$ (Heidelberg, Germany) and maintained in Endothelial
Cell Growth Medium (ECGM, PromoCell) supplemented with the provided supplementMix, P/S and $10 \% \mathrm{FBS}$. We confirmed that HUVECs expressed the endothelial markers CD31 and von Willebrand factor. As control cell type, Human Dermal Fibroblasts (adult) (HDFa) were purchased from Cascade Biologics (Portland, OR, USA) and grown in DMEM with $10 \%$ FBS. Cells were fed twice a week and on reaching $80 \%$ confluency they were passaged using $0.05 \%$ trypsin- $0.02 \%$ EDTA.

\section{Fluorescent labelling of cells}

HUVECs or HDFa were labelled with CellTracker Red (CTR) CMTPX and MSCs were labelled with CellTacker Green [CTG (5-chloromethylfluorescein diacetate)] both from Molecular Probes (Eugene, OR, USA) according to the manufacturer's instructions. In short, cells were trypsinised, centrifuged to pellet and the supernatant removed. Then the cells were resuspended in $5 \mu \mathrm{M}$ CTG or CTR in pre-warmed serum-free basal medium for 45 min at $37^{\circ} \mathrm{C}$. Labelling was terminated by addition of FBS and any unincorporated stain was removed by washing with complete culture medium twice.

\section{Co-culture spheroids of MSCs with endothelial or control cells}

We used a non-endothelial control cell type in order to maintain 3D spheroid size and conditions, the initiating cell density and the initiating MSC number. We selected human dermal fibroblasts as controls, representing a related stromal cell type, but lacking both endothelial and MSC characteristics. Co-culture spheroids of MSCs with HUVECs or HDFa were generated statically. In brief, equal numbers of suspended MSC and HUVEC cells as well as equal number of both MSC and HDFa (15,000 cells each per spheroid) were mixed, centrifuged and resuspended in co-culture media of DMEM: ECGM/ supplement mix (1:1) containing $10 \%$ FBS and $0.25 \%$ (w/v) methylcellulose (Sigma-Aldrich, St. Louis, MO, USA; M-0512, 4000 centipoises). Mixed cells were then seeded into nonadherent round-bottom 96-well plates (Fisher) to generate overnight MSC/HUVEC and MSC/ HDFa spheroids containing 30,000 cells /spheroid.

\section{Live/dead viability assay}

After 1, 3 and 7 days of co-culture in 3D, the cell viability of the spheroids was assessed with the live/dead viability/ cytotoxicity assay kit (Molecular Probes) using two probes, calcein AM for intracellular esterase activity and ethidium homodimer-1 (EthD-1) for plasma-membrane integrity. Spheroids were washed with PBS and a working solution containing $8 \mu \mathrm{M}$ of each label was added. After $40 \mathrm{~min}$ incubation at room temperature (RT) in the dark, live spheroids were observed under a confocal microscope (LSM 710, Zeiss, Oberkochen, Germany) taking images as a z-series, which were then condensed into a $3 \mathrm{D}$ projection image.

\section{Differentiation assays}

To induce osteogenic differentiation, spheroids were co-cultured in media supplemented with $5 \mathrm{mM}$ $\beta$-glycerophosphate, $50 \mu \mathrm{g} / \mathrm{mL}$ ascorbic acid phosphate 
and $10 \mathrm{nM}$ dexamethasone (all from Sigma-Aldrich) for up to 14 days before being stained for alkaline phosphatase activity with using Fast Red. For adipogenic differentiation, the medium was supplemented with $1 \mu \mathrm{M}$ dexamethasone, $500 \mu \mathrm{M}$ isobutylmethylxanthine, $100 \mu \mathrm{M}$ indomethacin and $1 \mu \mathrm{g} / \mathrm{mL}$ insulin (all from Sigma-Aldrich) for up to 14 days before identifying adipocytes by oil red $\mathrm{O}$ staining. To determine the effects of Wnt signalling in adipogenic differentiation, spheroids were grown in adipogenic differentiation medium in the presence and absence of the Wnt inhibitor Dkk-1 (100 ng/mL).

\section{Histochemical staining}

Spheroids were embedded in Tissue-Tek O.C.T. (Sakura Finetek USA, Torrance, CA, USA) and snap-frozen in liquid nitrogen. Cryosections $(10 \mu \mathrm{m})$ were obtained with a Leica CM3050S cryostat (Leica Microsystems, Wetzlar, Germany) and transferred to microscope slides (SuperFrost, Menzel/Thermo Fisher Scientific, Loughborough, UK). Alkaline phosphatase (ALP) activity was detected with $1 \mathrm{mg} / \mathrm{mL}$ Fast red TR (Sigma-Aldrich) and $0.2 \mathrm{mg} / \mathrm{mL}$ napthol AS-MX phosphate (Sigma-Aldrich), dissolved in $1 \% \mathrm{~N}, \mathrm{~N}$ dimethylformamide (Sigma-Aldrich) diluted in $0.1 \mathrm{M}$ Tris buffer at $\mathrm{pH}$ 9.2. Quantification of ALP was expressed as corrected total fluorescence (CTF) in which five randomly selected visual fields were examined in each of two independent experiments and analysed by Image J analysis software. Von Kossa staining was used to identify sites of mineralisation. Briefly, sections were fixed in $4 \%$ paraformaldehyde for $5 \mathrm{~min}$ and incubated in $1 \%$ silver nitrate (Thermo Fisher Scientific) on a light box at room temperature for 10-60 min. The sections were then washed three times with $\mathrm{dH}_{2} \mathrm{O}$ and incubated in $2.5 \%$ sodium thiosulphate (Thermo Fisher Scientific) for $5 \mathrm{~min}$ before final two washes in $\mathrm{dH}_{2} \mathrm{O}$. For adipocytic staining, cells were fixed in $60 \%$ isopropanol for $5 \mathrm{~min}$ before incubating in $0.3 \%$ oil red O (Sigma-Aldrich) solution in $60 \%$ isopropanol for $30 \mathrm{~min}$. Nuclei were also counterstained with haematoxylin. After three washes in $\mathrm{dH}_{2} \mathrm{O}$, samples were mounted in glycerol/gelatine solution (Fluka/SigmaAldrich) before imaging on a Leica DMLA microscope.

\section{Immunocytochemistry and Western blot analysis}

For immunofluorescence, spheroids were embedded and cryosectioned as described above. Sections were transferred to microscope slides (SuperFrost, Menzel), immersed in PBS and treated with ice-cold acetone for $30 \mathrm{~min}$. After blocking with $10 \%$ goat serum in PBS for $1 \mathrm{~h}$, the sections were incubated with primary antibodies [rabbit anti CD31 1:100, Abcam, Cambridge, UK; mouse anti-CD31 1:100, Santa Cruz, Santa Cruz, CA, USA; rabbit anti-Ki67 1:200, Abcam; mouse anti-active nuclear $\beta$-catenin $(\mathrm{ABC}$, which identifies the active, dephophorylated form of $\beta$-catenin) 1:200, Millipore, Billerica, MA, USA; rabbit anti-p-Smad 1/5/8 1:100, Cell Signaling Technology, Beverly, MA, USA] diluted in PBS $0.1 \%$ bovine serum albumin (BSA, Sigma-Aldrich) in a humid chamber overnight at $4{ }^{\circ} \mathrm{C}$. After washing three times with PBS, sections were incubated for $1 \mathrm{~h}$ at room temperature (RT) with conjugated secondary antibodies [anti-rabbit FITC (Sigma-Aldrich) 1:200; antimouse FITC (Sigma-Aldrich) 1:200; anti-rabbit Alexa fluor 594 (Invitrogen, Carlsbad, CA, USA) 1:400]. After the nuclei were stained with $1 \mu \mathrm{g} / \mathrm{mL} 4$, 6-diamidino2-phenylindole (DAPI, Molecular Probes) for another $10 \mathrm{~min}$, samples were mounted in Vectashield (Vector Laboratories, Burlingame, CA, USA) and examined using an LSM 710 META confocal microscope (Zeiss). To determine the number of Ki67-positive cells, at least six cryosections of different co-culture spheroids derived from three independent experiments, using different donors, were analysed using $20 \times$ magnification. For ABC and p-Smad 1/5/8 image quantification, numbers of DAPIpositive and ABC- or p-Smad 1/5/8-positive nuclei were determined using Fiji software (http://pacific.mpi-cbg.de). The percentage of cells with nuclear $\beta$-catenin or $\mathrm{p}$-Smad $1 / 5 / 8$ was then calculated for both MSC/HUVEC and MSC/HDfa spheroids. Results, representing mean values \pm SE from two independent donors, were statistically analysed using the independent sample $t$-test assuming equal variances. Levels of $\beta$-catenin were also quantified by western blot analysis. MSC/HUVEC and MSC/HDFa co-culture spheroids were collected, washed twice in cold $1 \mathrm{x}$ PBS before being collected into a universal containing $200 \mu \mathrm{L}$ of RIPA buffer with protease inhibitor cocktail 3 (Calbiochem/Merck, Darmstadt, Germany) and sonicated on ice at $20 \mathrm{kHz}$ for $20 \mathrm{~s}$. After sonication, samples were centrifuged for $5 \mathrm{~min}$ at $16,000 \mathrm{~g}$ at $4{ }^{\circ} \mathrm{C}$ and the supernatants collected for analysis. Whole cell lysates were subjected to SDS-PAGE followed by western blotting with an overnight incubation at $4{ }^{\circ} \mathrm{C}$ with anti-active $\beta$-catenin (anti-ABC, Millipore) (1:500 in 1x TBS-T) or for $1 \mathrm{~h}$ at RT with anti-GAPDH (GeneTex, Irvine, CA, USA) (1:4000 in $1 \mathrm{x}$ TBS-T). Following further washes in TBS-T, the membrane was incubated with horseradish peroxidase (HRP) conjugated anti-mouse secondary antibody (1:2000 in 1x TBS-T; Dako, Glostrup, Denmark) for $1 \mathrm{~h}$ at RT. Any unbound antibody was removed with three washes in TBS-T and specific antibody binding was visualised using enhanced chemiluminescence (ECL) reagents (GE Healthcare; www.gehealthcare.com) with exposure to CL X-Posure film (Thermo Scientific). Between antibodies, membrane was stripped at $60{ }^{\circ} \mathrm{C}$ for $20 \mathrm{~min}$ in stripping buffer (100 mM $\beta$-mercaptoethanol, $2 \%$ SDS, $62.5 \mathrm{mM}$ Tris-HCl ( $\mathrm{pH}$ 6.7) with agitation. Protein bands were quantified using Image J software 1.43 (NIH, Bethesda, MD, USA) and normalised to the levels of GAPDH (loading control).

\section{Transmission electron microscopy (TEM)}

$3 \mathrm{D}$ co-cultures were fixed overnight at $4{ }^{\circ} \mathrm{C}$ in $2.5 \%$ glutaraldehyde then $1 \%$ osmium tetroxide on ice for $1 \mathrm{~h}$, dehydrated in graded ethanol series, incubated in epoxy-propane for $25 \mathrm{~min}$ at RT before being infiltrated with epoxy resin and polymerised for $48 \mathrm{~h}$ at $60{ }^{\circ} \mathrm{C}$ prior to sectioning. Resulting sections were transferred to propylene oxide and embedded in epoxy resin. Semithin sections were stained with $1 \%$ methylene blue. The sample was further sectioned into ultrathin slices $(70 \mathrm{~nm})$, contrasted with uranyl acetate and lead citrate and observed on a FEI (Hillsboro, OR, USA) Tecani G2 transmission electron microscope. 
a

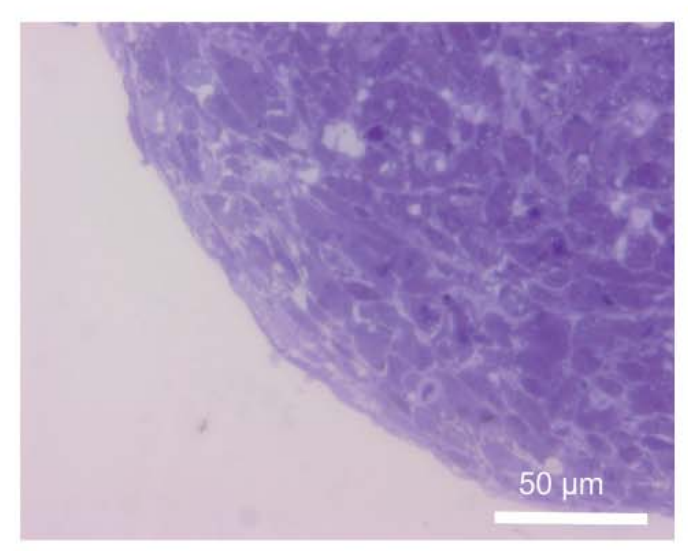

b

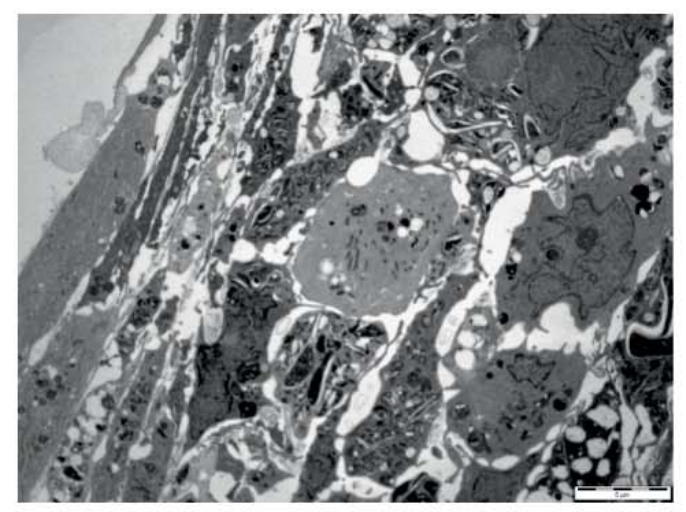

C

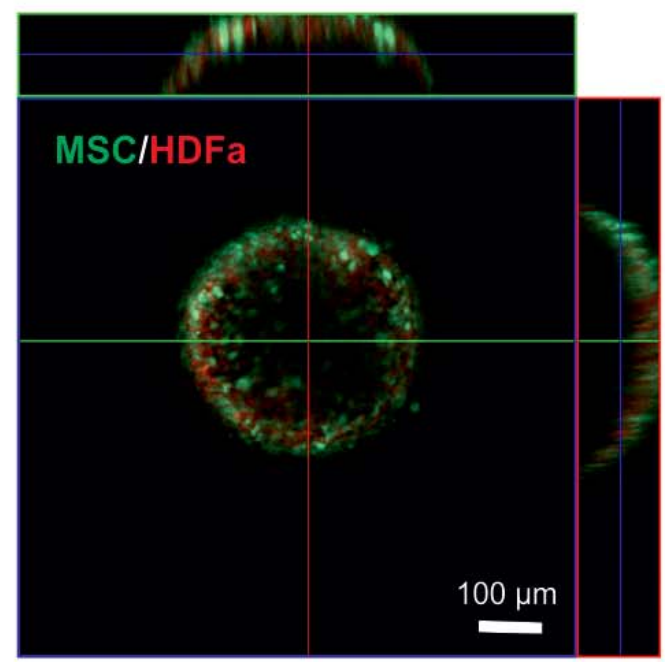

MSC:HUVEC
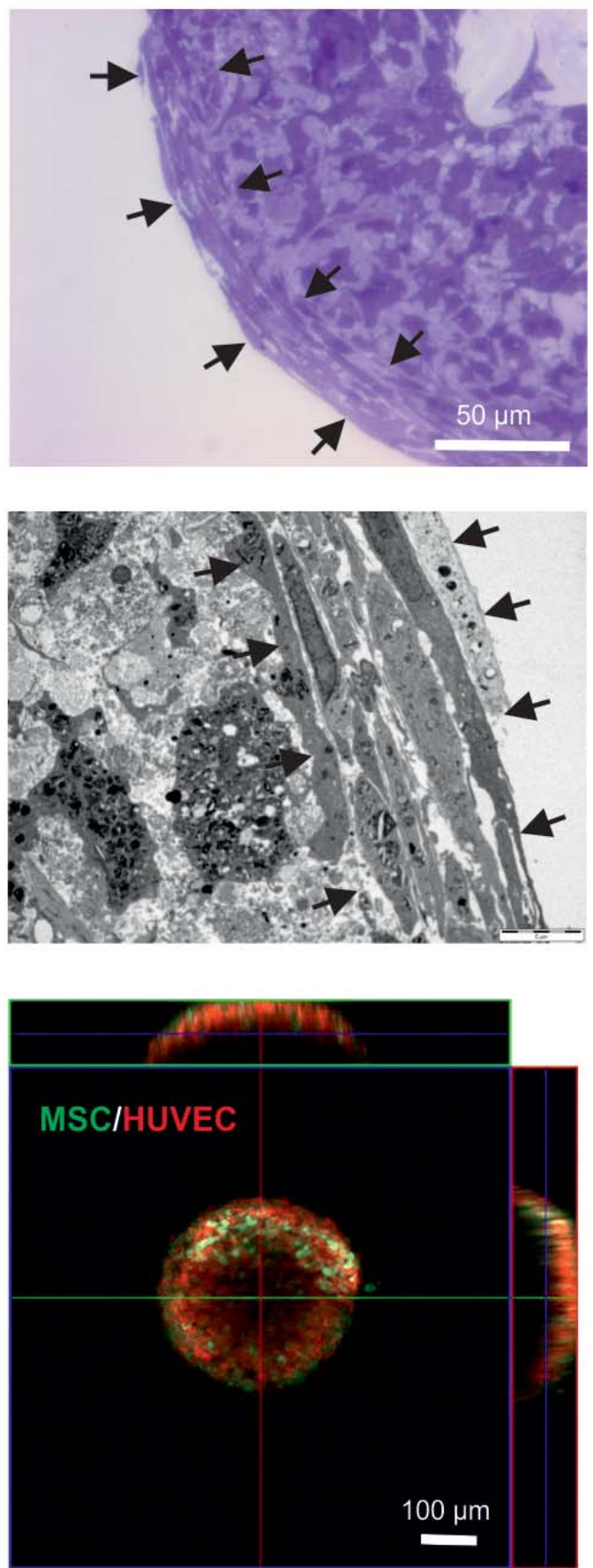

Fig. 1. 3D co-cultures of MSC with HUVECs or HDFa (controls) after 7 days in culture. (a) and (b): Light and TEM images of the co-cultures show flattened, elongated cells at the periphery indicated by the arrows. (c): Confocal z-stack images of the MSCs (green) with HUVECs or HDFa (red) showing a predominance of endothelial cells (red staining, right panel) at the spheroid periphery. Scale bars: $50 \mu \mathrm{m}$ (a), $5 \mu \mathrm{m}$ (b), $100 \mu \mathrm{m}$ (c).

\section{Results}

Self-assembly in co-culture spheroids

MSCs and HUVECs were directly co-cultured at a 1:1 cell ratio for 7 days in non-adherent U-shaped bottom 96 well plates. Co-cultures of MSCs and HDFa served as controls. Under optimised growth conditions, mixed spheroids were formed overnight. Histological analysis of sections showed a layer of endothelial-like cells that were more elongated and flattened at the periphery of MSC/HUVEC spheroids compared to MSC/HDFa controls (Fig. 1a) with clear boundaries between the two cell morphologies. TEM images also revealed a continuous arrangement of elongated cells on the outer surface of the MSC/HUVEC spheroids by day 7 with more rounded cells at the spheroid interior (Fig. 1b). In order to track cells in a 3D co-culture, MSCs were fluorescently labelled with cell tracker green, whereas HUVECs and HDFa were labelled with a red 


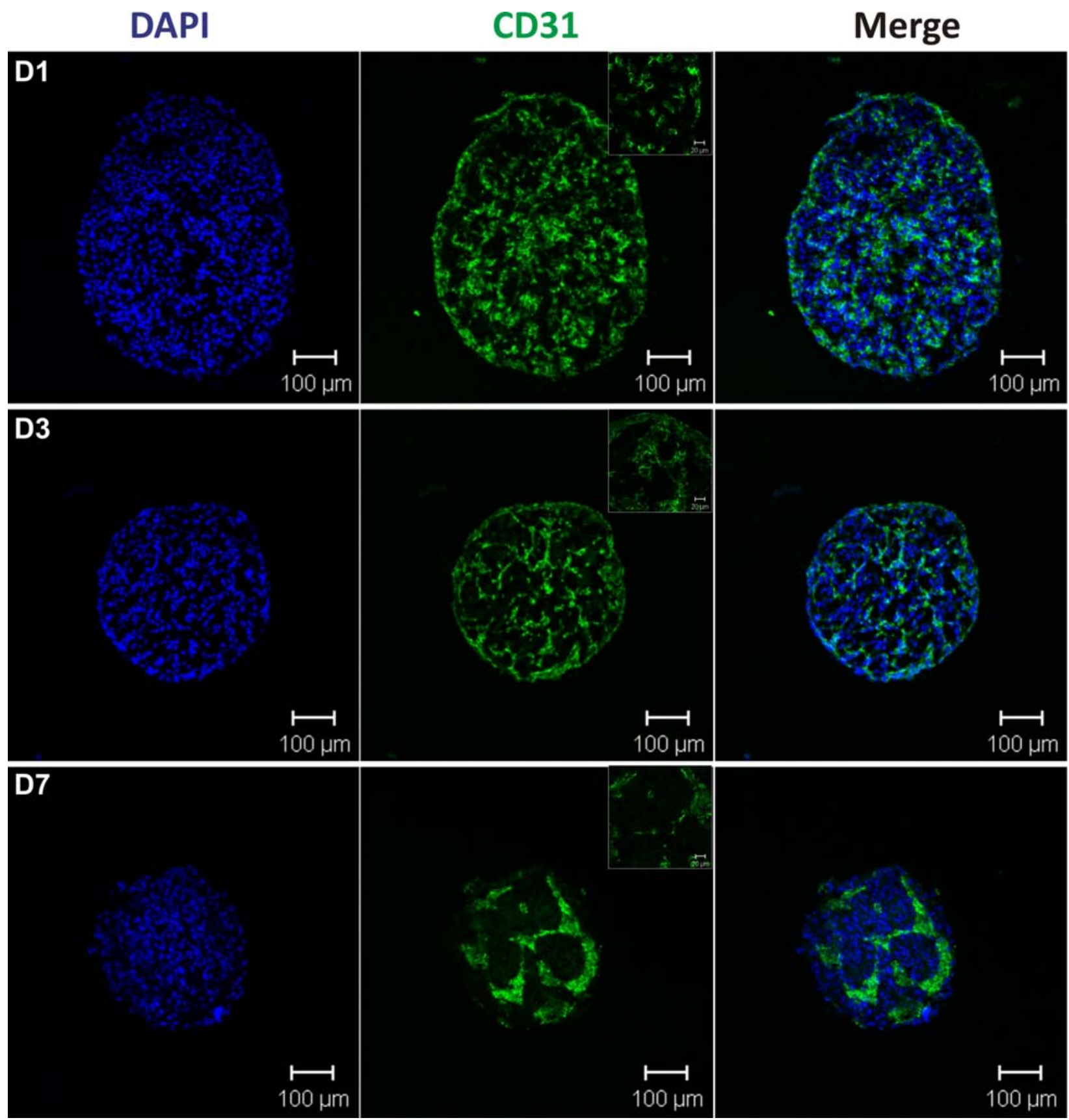

Fig. 2. Confocal images of CD31 labelling of MSC/HUVEC spheroids at day 1, 3 and 7. CD31 positive cells (HUVECs) were observed predominantly around the periphery in co-culture spheroids, with some intra-spheroid islands of CD31-positivity. With time, HUVECs associated to form increasingly substantial networks throughout the 3D MSC structure. DAPI nuclear counterstain also shown. Scale bars: $100 \mu \mathrm{m}$.

fluorescent cell tracker stain. After 7 days in co-culture, spheroids were examined by confocal microscopy. Despite the fact that both cell types were introduced in co-cultures simultaneously as single cell suspensions, HUVECs and MSCs were shown to self-assemble and form organised structures with segregated cell-type partitioning, with HUVECs assuming a predominantly peripheral distribution (Fig. 1c).

To determine the time-course of MSC/HUVEC selfassembly and the organisation of cells throughout the depth of the spheroid, we used CD31 immunostaining on cryosections. After 1, 3 and 7 days of co-culture, CD31 localisation confirmed the peripheral distribution of HUVECs with MSCs and also identified occasional central HUVEC foci (day 1) which developed into primitive endothelial cell networks that became more established over time. Moreover, the spheroid did not increase in size but progressively compacted (Fig. 2).

\section{Viability and proliferation of cells in 3D}

Because cells, particularly in the centre of spheroids, may have reduced access to nutrients and oxygen, it was necessary to establish whether the cells remained viable and to investigate whether co-culture with HUVECs had 


\section{MSC:HDFa}
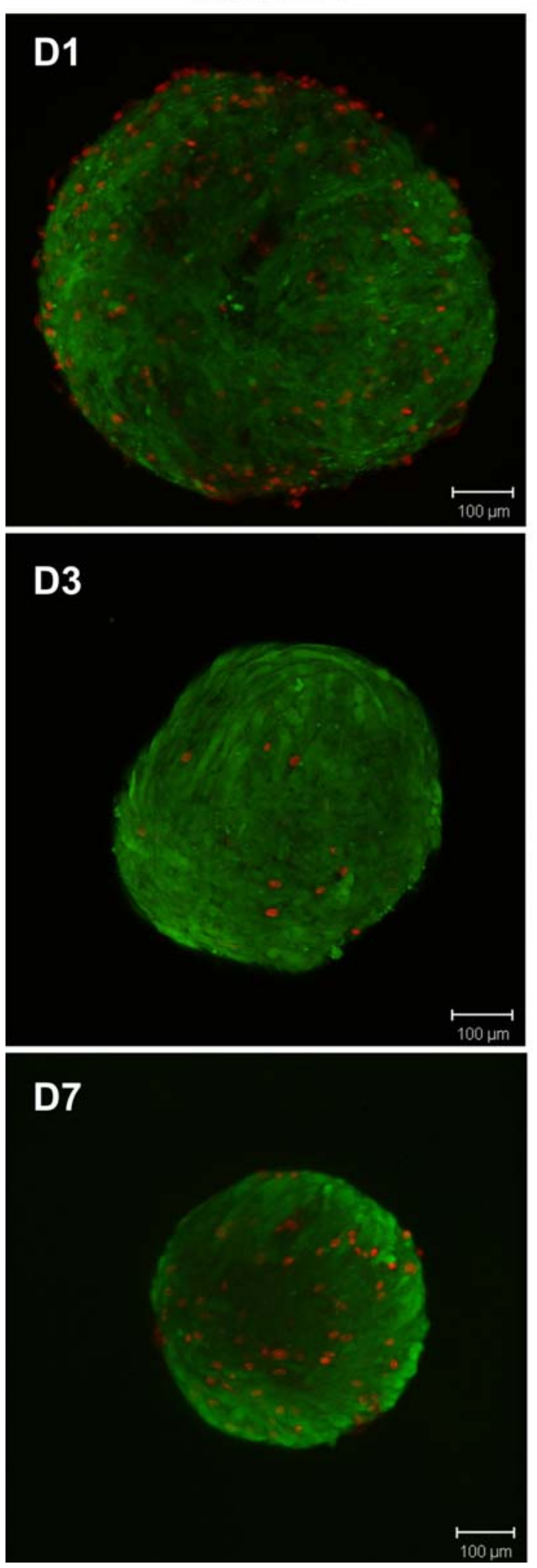

\section{MSC:HUVEC}
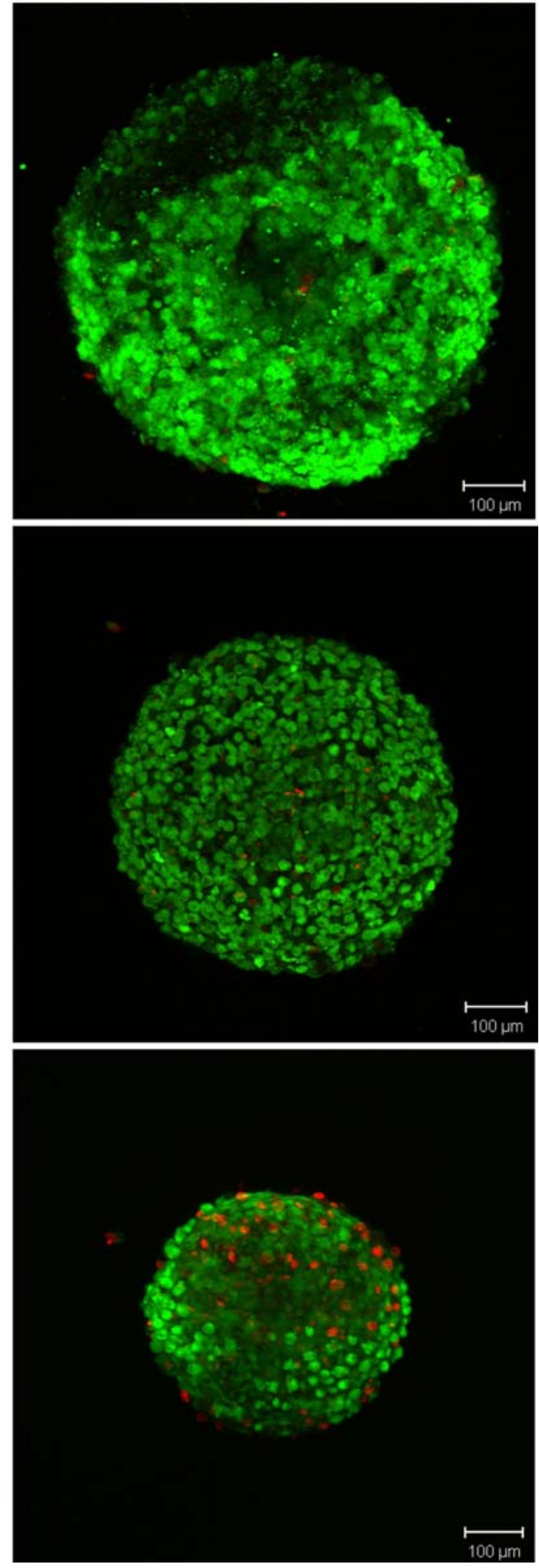

Fig. 3. Live (green)/dead (red) staining for co-culture MSC/HUVEC spheroids versus MSC/HDFa controls. Cell viability was determined after 1, 3 and 7 days of culture. Images are shown as a 2D composite of a z-series of images. Scale bars: $100 \mu \mathrm{m}$.

any influence on the MSC viability using a live/dead fluorescent viability assay. After 7 days of co-culture, the majority of the cells were viable (green) in both $\mathrm{MSC} /$ HUVEC and MSC/HDFa spheroids with the number of dead cells increasing slightly when the incubation period was extended from day 3 to day 7 (Fig. 3). Quantification by image analysis of these data did not detect any significant differences in cell death between MSC/ HUVEC and MSC/HDFa spheroids (data not shown). To determine proliferative activity, sections were stained 
a
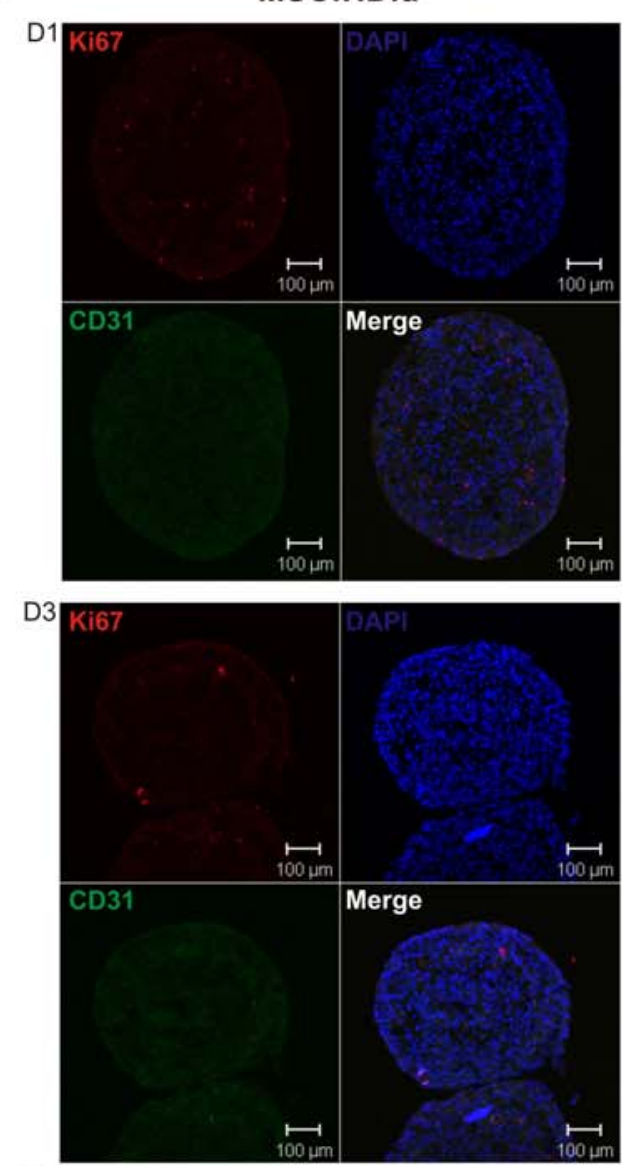

D7 Ki67
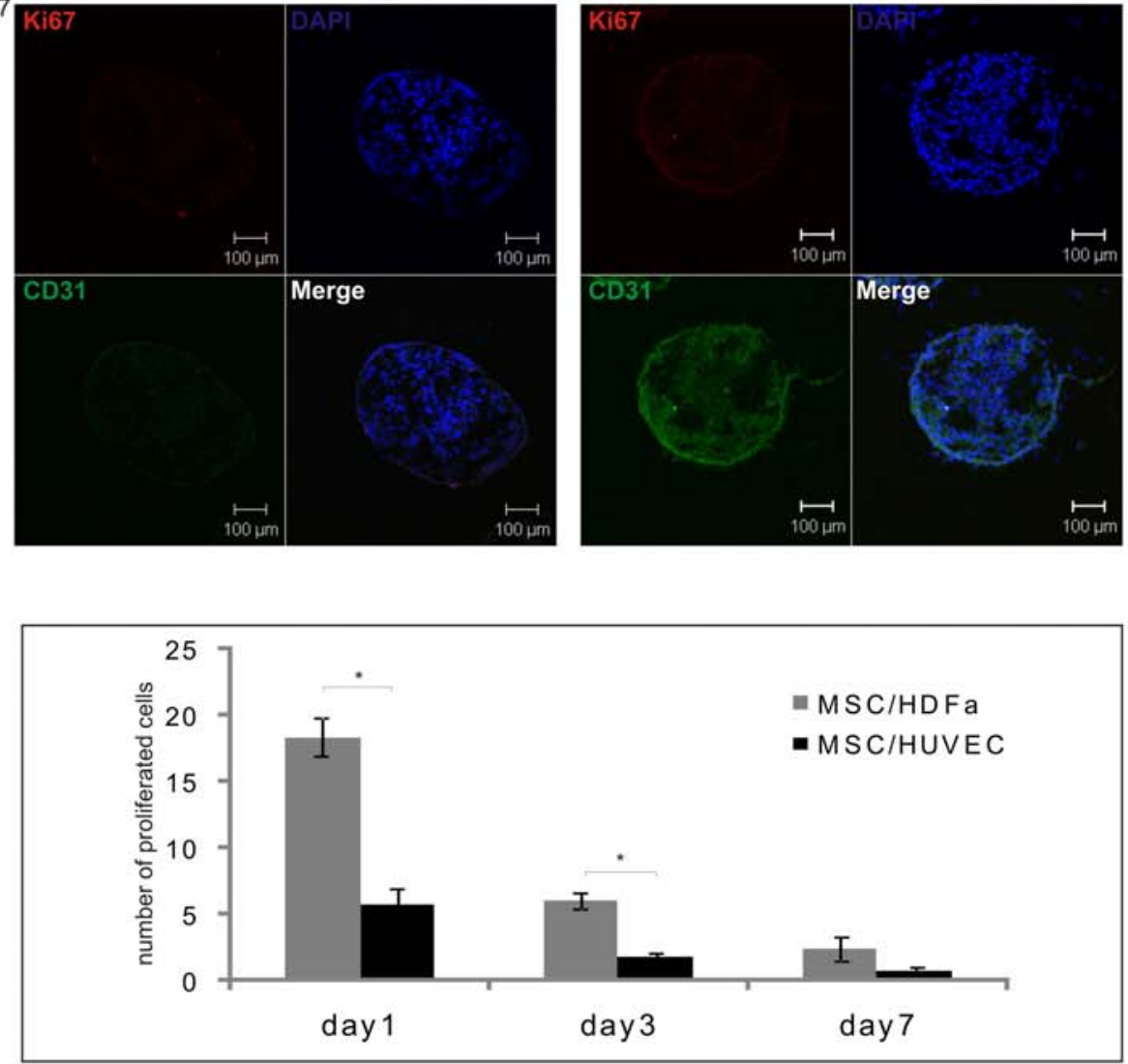

Fig. 4. Immunofluorescent localisation of Ki67 in 3D co-cultures of MSC/HUVEC and MSC/HDfa. (a) Ki67 staining (red), CD31 staining (green) and merged images with a DAPI nuclear counterstain are shown at day 1,3 and 7. (b) Histogram showing the number of proliferating Ki67-positive cells in spheroids of MSC/HUVEC and $\mathrm{MSC} / \mathrm{HDFa}, n=3, * P<0.05$. 

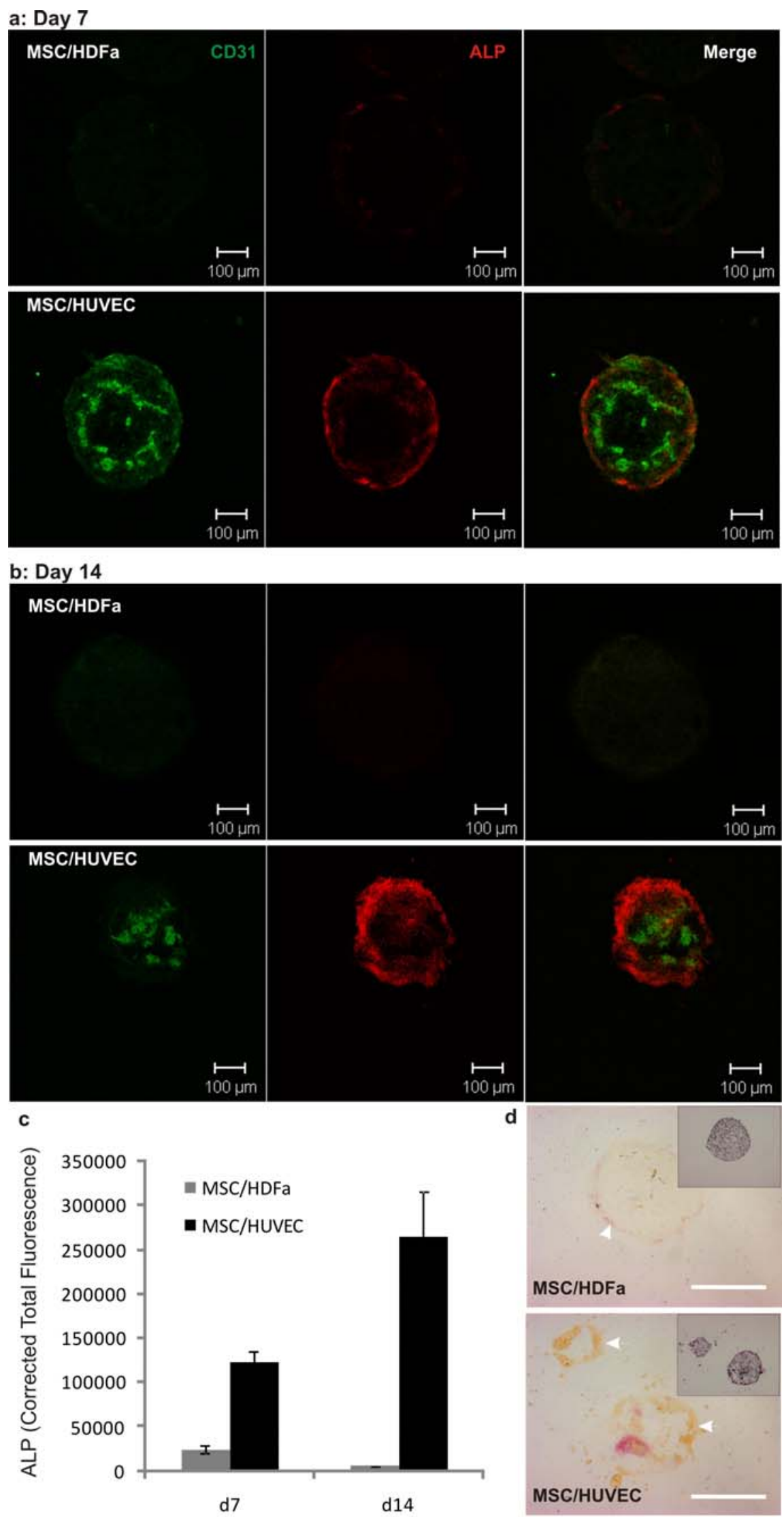

Fig. 5. Osteogenic differentiation in 3D co-culture of MSCs and HUVECs or HDFa (as control). Alkaline phosphatase (ALP) enzyme reactivity (red) in MSC/HUVEC and MSC/HDFa spheroids at day 7 (a) and day 14 (b) following osteogenic differentiation. ALP-positive cells were CD31 negative but in close proximity to the CD31 positive endothelial cells (green). Levels of ALP fluorescence were quantified by image analysis, mean data \pm SE shown (c) von Kossa staining of spheroids to detect mineralisation (brown, arrows) at day 14, inset shows haematoxylin-stained serial sections, scale bars $=200 \mu \mathrm{m}$ (d). CD31-positive HUVECs enhanced osteogenic differentiation of MSCs compared to controls. 
MSC:HDFa

MSC:HUVEC
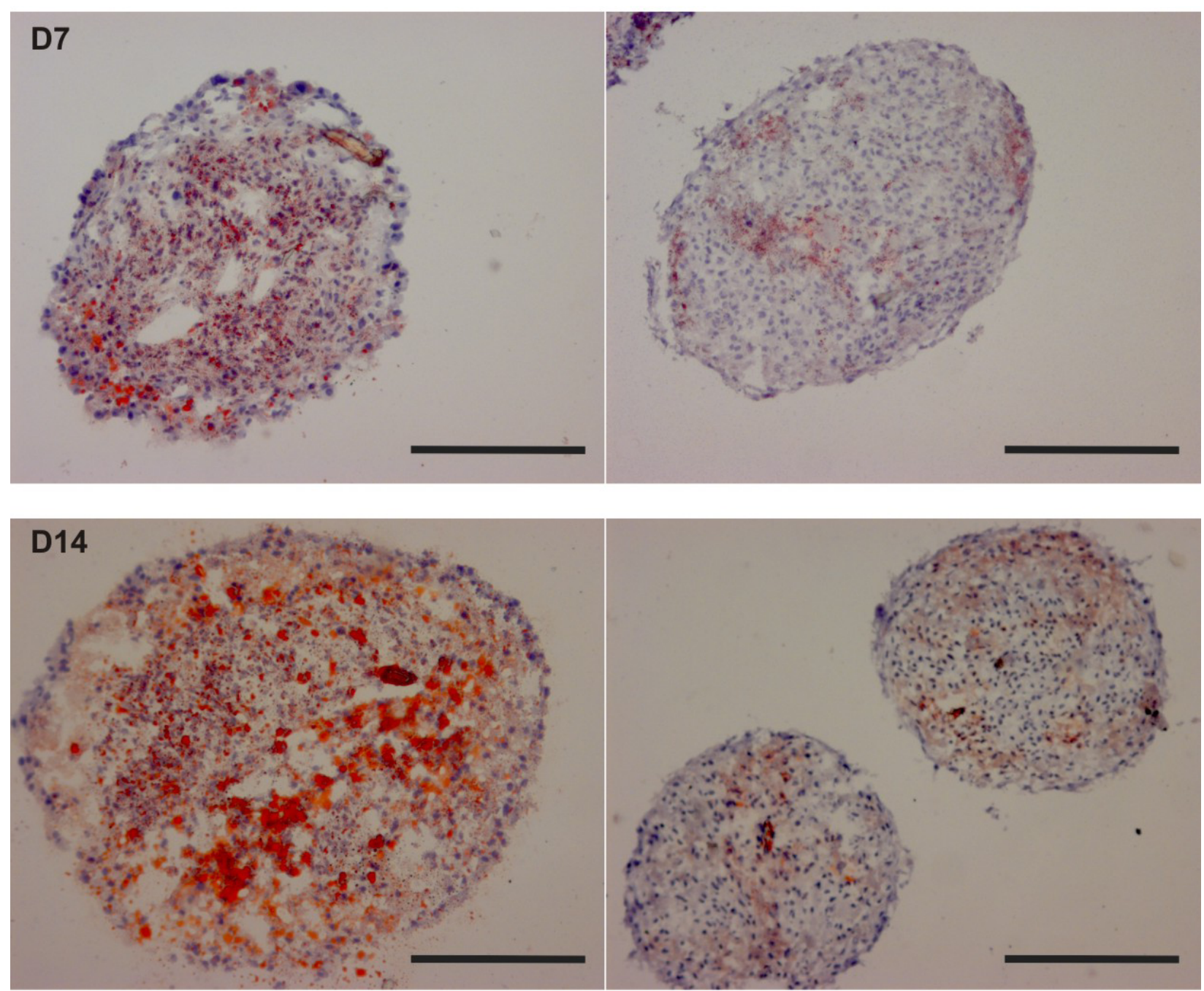

Fig. 6. Adipogenic differentiation in $3 \mathrm{D}$ co-culture of MSCs and HUVECs. Adipogenic supplements were added to co-cultures of MSCs with HUVECs or HDFa (as control) for 14 days. Cryosections of MSC/HUVEC and MSC/ HDFa spheroids were taken at day 7 and 14 following adipogenic differentiation and stained for oil red O (orange/ red) to determine lipid droplet accumulation with a haematoxylin counterstain. HUVECs inhibited adipogenic differentiation of MSCs compared to HDFa controls. Scale bar: $250 \mu \mathrm{m}$.

for Ki67, which is a cell cycle-related nuclear protein expressed by proliferating cells in all phases of the active cell cycle; CD31 staining was used to discriminate between HUVECs and MSCs. Results show that Ki67 positivity was decreased in HUVEC/MSC spheroids compared to HDFa controls (Fig. 4a). Quantification of Ki67-positive cells confirmed that the numbers of cycling MSCs was significantly reduced in the presence of HUVECs (Fig. 4b). Lack of CD31 immunostaining in MSC/HDFa controls confirmed the specificity of the antibody and absence of any spontaneous endothelial differentiation of MSCs in 3D.

\section{Osteogenic and adipogenic differentiation in MSC/ HUVEC spheroids}

MSC/HUVEC and MSC/HDFa spheroids were cultured in the presence of osteogenic and adipogenic supplements for 14 days with spheroids taken at days 7 and 14 for cryosectioning and histochemical staining. Initial analysis by light microscopy demonstrated that MSC/HUVEC spheroids enhanced osteogenic differentiation, as shown by alkaline phosphatase staining, especially at the outer surface of the spheroid at both day 7 and 14 compared to MSC/HDFa spheroids. To determine the localisation of osteogenic cells within the 3D heterocellular structure, we used CD31 immunofluorescent staining and the fluorescent properties of Fast Red disclosing alkaline phosphatase activity. Results confirmed that HUVECs enhanced osteogenic differentiation, on days 7 and 14, compared to HDFa controls as shown by elevated alkaline phophatase levels (Fig. 5a, b). CD31-expressing cells were in close proximity to Fast Red-positive cells, but did not co-localise (Fig. 5a and b). Quantification by image analysis confirmed the increased levels of alkaline phosphatase (Fig. 5c), which were accompanied by elevated mineralisation (von Kossa 


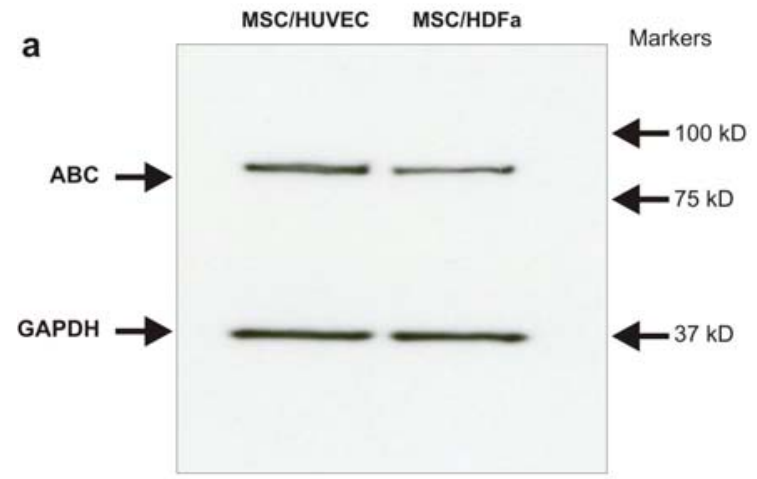

b no DKK-1

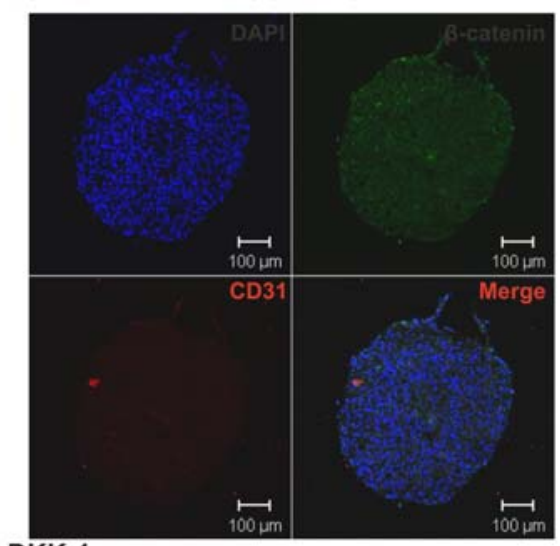

DKK-1

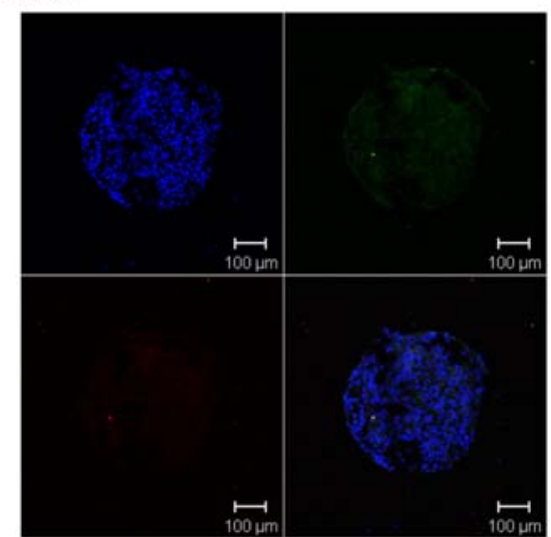

...

c

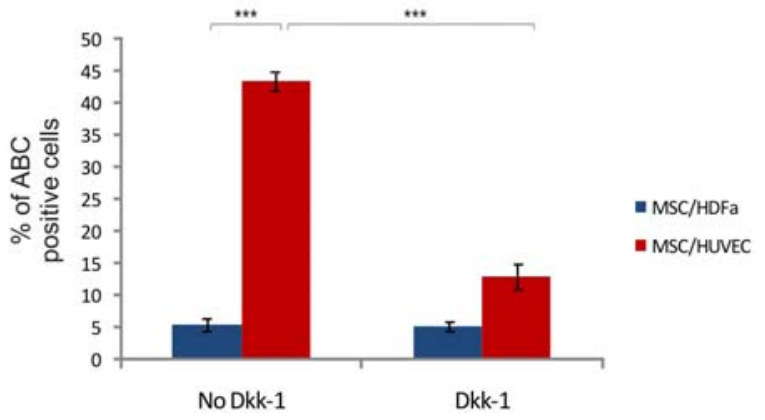

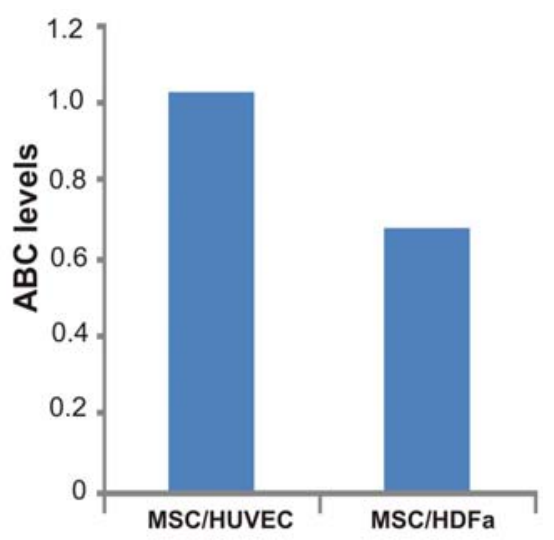

MSC:HUVEC
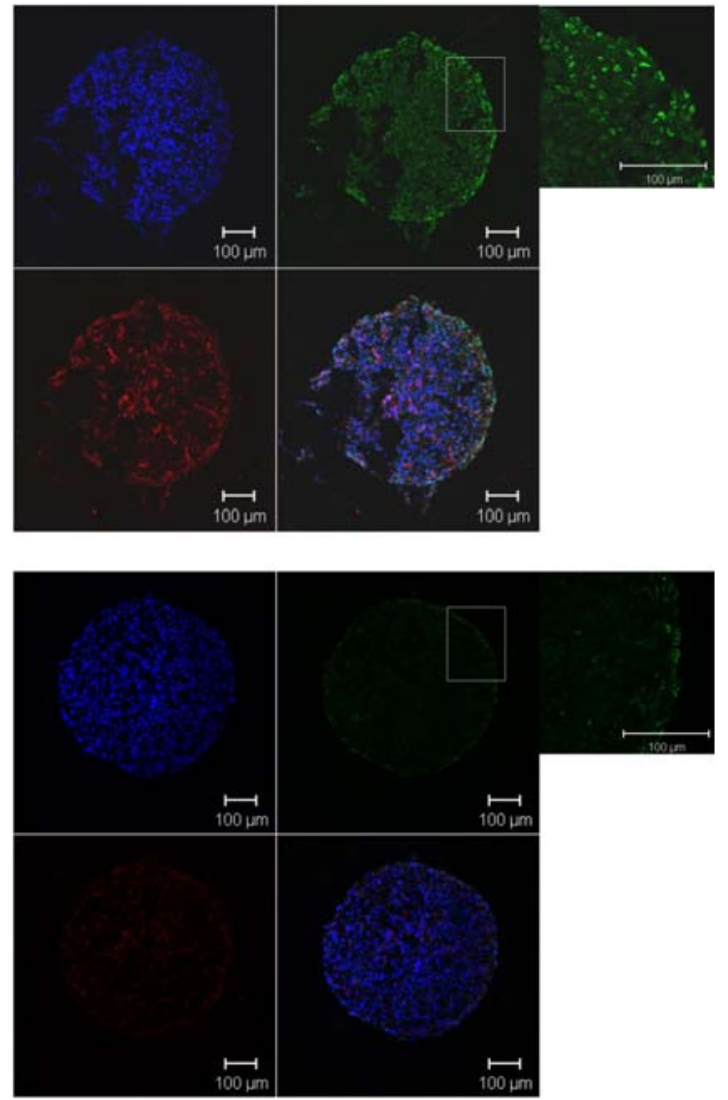

Fig. 7. Active $\beta$-catenin expression in 3D MSC/HUVECs compared to MSC/HDFa. Western blot analysis of active $\beta$-catenin (ABC) levels in 3D co-cultures, compared to GAPDH loading control (a, left panel). Band intensities were quantified by densitometry, normalised to GAPDH (a, right panel). Active $\beta$-catenin staining (green), CD31 (red) and merged images with DAPI nuclear counterstain are shown (b) MSCs co-cultured for $72 \mathrm{~h}$ with CD31 positive cells (HUVECs) showed increased expression of nuclear $\beta$-catenin compared to controls. Nuclear $\beta$-catenin staining in MSC/HUVEC spheroids was inhibited when treated with DKK-1 (b). The percentage of cells with ABC staining was calculated using Fiji software (c). Quantitative data represent mean values $\pm \mathrm{SE}$ from two independent donors, $n=3$. ABC staining increased significantly in MSC/HUVEC spheroids compared to MSC/HDFa controls but was inhibited after Dkk-1 treatment $(t$-test; $* * P<0.01, * * * P<0.001)$. 
a
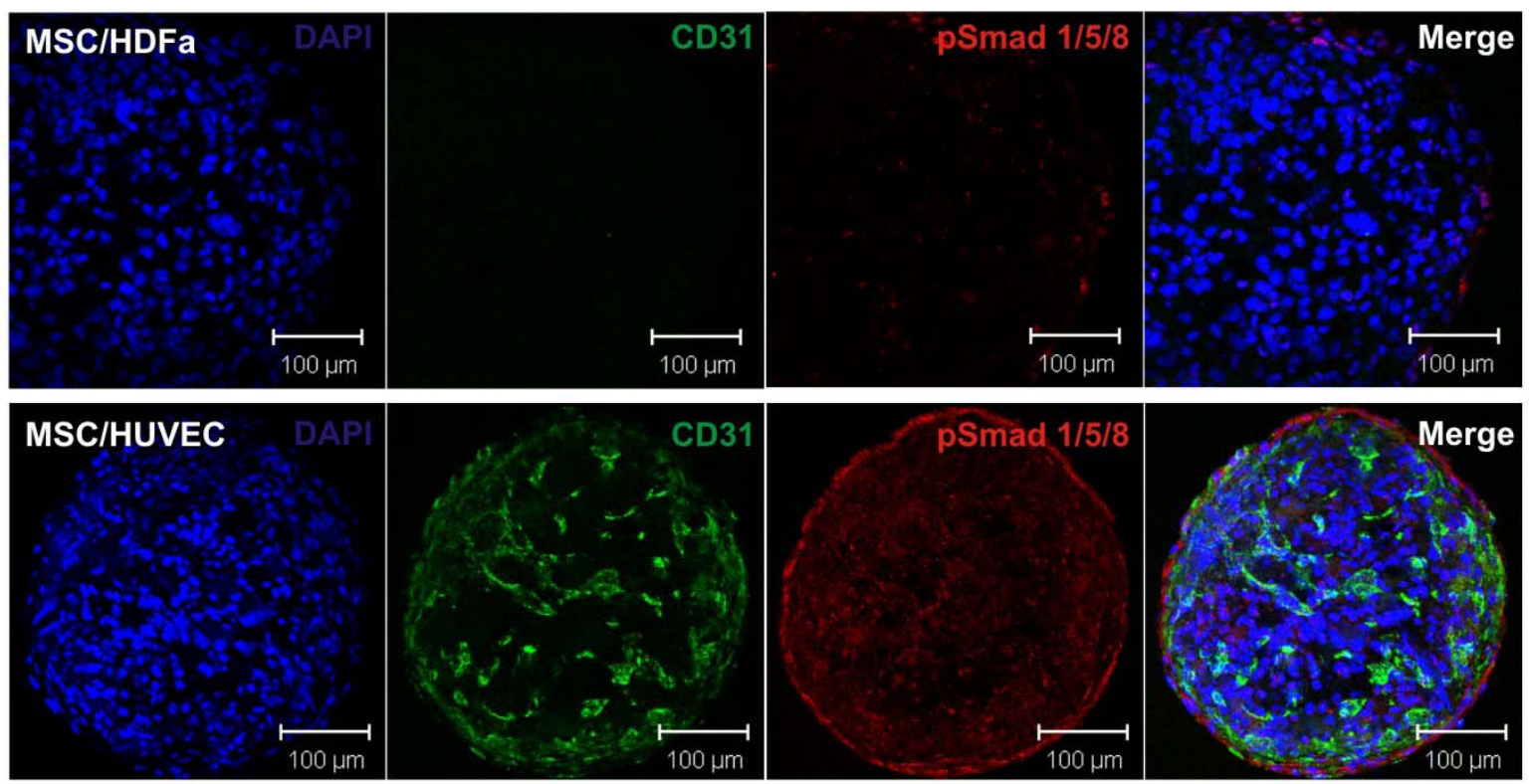

b

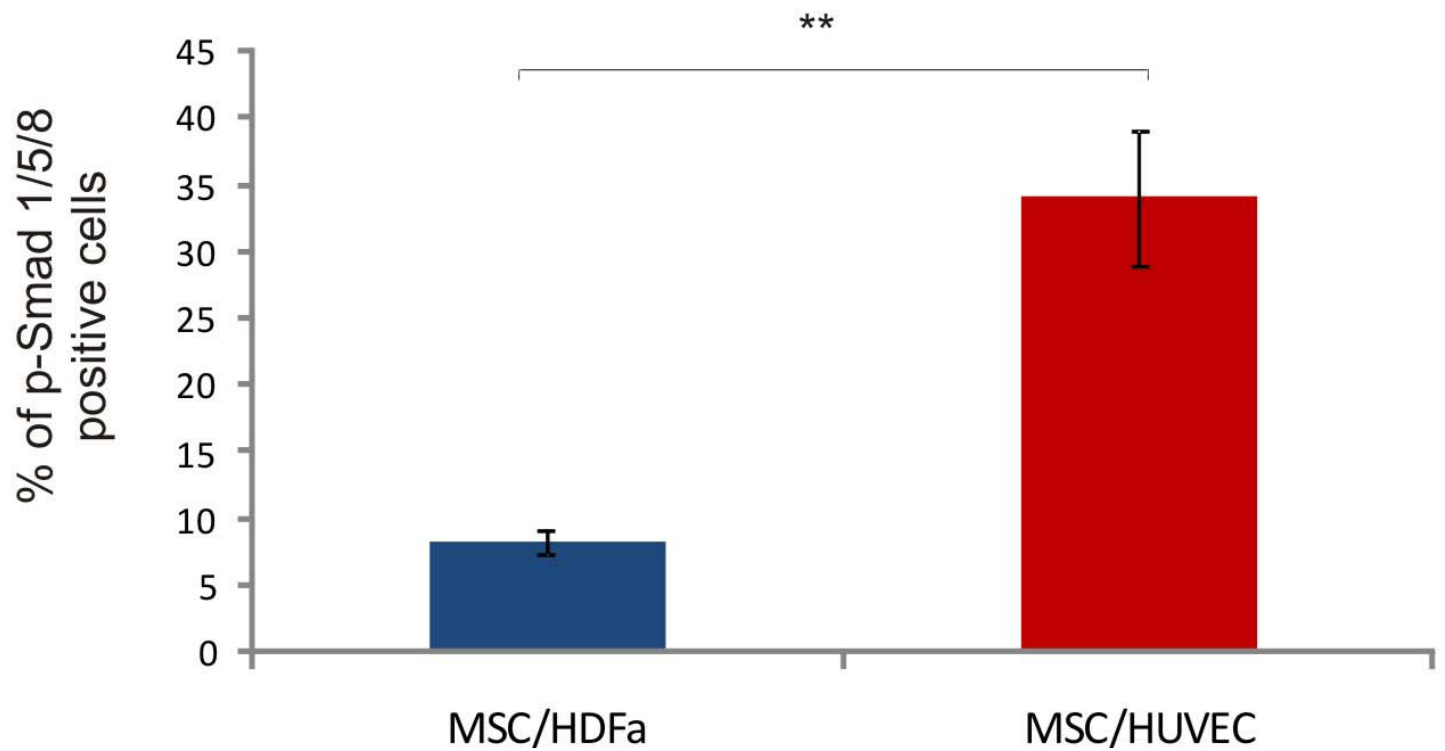

Fig. 8. Immunostaining of pSmad1/5/8 in osteogenic spheroids. pSmad1/5/8 expression (red) was intense, particularly at the periphery of MSC/HUVEC sections compared to MSC/HDFa controls after 7 days of osteogenic differentiation. CD31 (green), DAPI nuclear staining and merged images are also shown (a). The percentage of cells with p-Smad 1/5/8 staining was calculated using Fiji software (b). Quantitative data represent mean values \pm SE from two independent donors, $n=3$. P-Smad1/5/8 staining increased significantly in MSC/HUVEC spheroids compared to MSC/HDFa controls ( $t$-test; ** $P<0.01)$.

staining, Fig. 5d) in 3D MSC/HUVECs, when compared to controls. Conversely, under adipogenic conditions, MSC/HDFa spheroids accumulated lipid-filled, Oil Red O-positive cells and increased in diameter, whereas these indicators of adipogenic induction were markedly reduced in MSC/HUVEC spheroids at days 7 and 14 (Fig. 6).

\section{Analysis of Wnt and BMP signalling in 3D co- cultures}

We previously screened whole genome expression profiles, to integrate genes encoding secreted HUVEC proteins with those encoding cell surface MSC proteins (Saleh et al., 2011). These analyses identified Wnt and BMP signalling pathways as potentially important mediators for the crosstalk between HUVECs and MSCs. To determine whether endogenous $\beta$-catenin-dependent Wnt signalling was activated during co-culture of HUVEC and MSCs, western blot analyses were performed, which indicated increased active $\beta$-catenin levels in 3D MSC/HUVECs, when compared to controls (Fig. 7a). Cryosections of undifferentiated spheroids, after $72 \mathrm{~h}$ of co-culture, were also immunostained for nuclear active $\beta$-catenin. HUVECs were found to activate Wnt signalling with increased expression of active nuclear $\beta$-catenin in CD31-negative MSCs compared to controls, which was decreased following exposure to the Wnt antagonist, Dkk-1 for $24 \mathrm{~h}$ 
MSC:HDFa
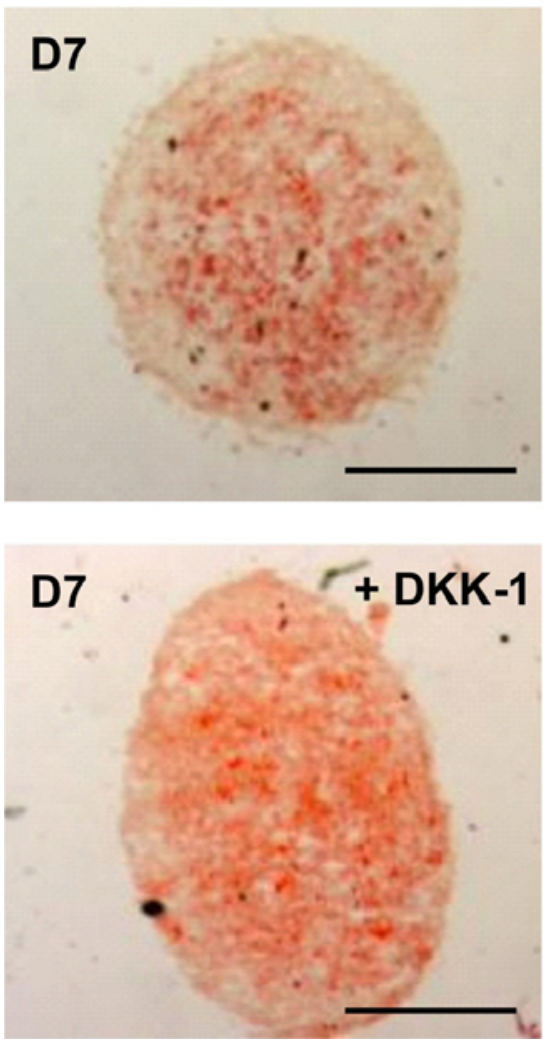

MSC:HUVECs

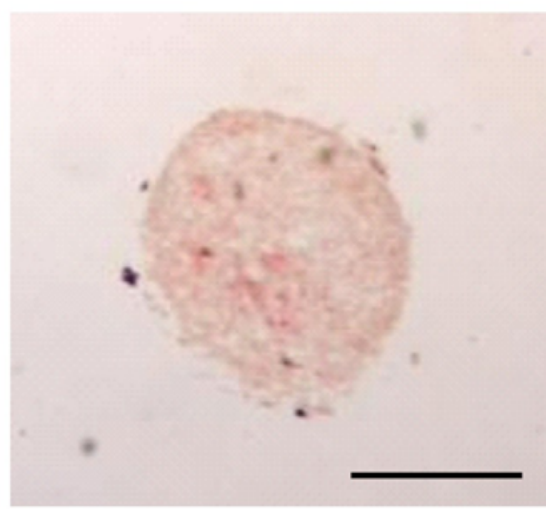

+ DKK-1



Fig. 9. Effects of Wnt signalling inhibition on adipogenesis in 3D co-cultures. 3D MSC/HUVEC and MSC/HDFa (controls) were subjected to adipogenic stimuli for 7 days in the presence and absence of the Wnt inhibitor Dkk-1 (100 ng/mL). Oil Red O staining confirmed decreased adipogenesis in MSC/HUVECs compared to MSC/HDFa control co-cultures, which was rescued following exposure to Dkk-1. Scale bar $=250 \mu \mathrm{m}$.

(Fig. $7 \mathrm{~b}$ and c). In osteogenic assays, immunostaining for pSmad 1/5/8, a downstream mediator of BMP signalling, at day 7 of differentiation showed increased expression, particularly at the periphery of the spheroids, with HUVECs causing enhanced pSmad expression in CD31negative MSCs compared to HDFa controls (Fig. 8).

Given the clear inhibitory effect HUVECs had on MSC adipogenic differentiation and the known suppressive effects of Wnt signalling on adipogenesis, we determined how modified Wnt signalling affected MSC adipogenesis when co-cultured with HUVECs in 3D. We confirmed that HUVECs induced inhibition of adipogenesis in MSC 3D co-cultures and that this inhibitory effect could be rescued by application of Dkk1 (Fig. 9).

\section{Discussion}

In vivo, cells do not exist in a monotypic cellular environment, but inhabit a complex, multi-component milieu. Stem cells occupy privileged sites, where strict environmental conditions are met to optimally support their specific needs. It is becoming increasingly necessary to consider the transition from conventional, flat 2D culture methods to $3 \mathrm{D}$ cultures in stem cell research to more closely recapitulate the local cellular environment and thus more accurately reflect the cells' in vivo behaviour (Saleh and Genever, 2011). The appropriate ex vivo manipulation of MSCs is likely to enhance their clinical value when used in cell-based therapies.

MSCs are increasingly thought to occupy a perivascular niche and therefore interact with the local vascular environment (Shi and Gronthos, 2003; da Silva et al., 2006; Crisan et al., 2008b; Carrion et al., 2010) either through interactions with soluble molecules, ECM or neighbouring cells. Our previous work focused on the effect of factors secreted by HUVECs on MSC activity (Saleh et al., 2011), other studies by Lozito et al. (2009) have highlighted the influence of endothelial cell matrix on MSC differentiation (Lozito et al., 2009). Here, we determined the interactions between MSCs and HUVECs in a 3D co-culture model, focusing not only on the differentiation capacity of MSCs, but also on MSC proliferation and major candidate signalling pathways implicated in the control of MSC behaviour such as Wnt and BMP. In addition, we examined the self-organisation of MSCs and endothelial cells during co-culture, as a model to study physiological cell-assembly phenomena that occur during tissue morphogenesis and development - which may impact on approaches to tissue reconstruction and regenerative medicine. We showed that initially randomly mixed MSCs and HUVECs underwent spontaneous self-assembly into a segregated 3D structure, 
with endothelial cells localising predominantly at the periphery of the spheroid over time. Stahl et al. also demonstrated that co-culture of human primary osteoblasts and human endothelial cells led to the latter cells forming a ring-like structure at the outer regions of the co-spheroid (Stahl et al., 2004). The mechanisms by which cells selforganise are not yet known. But, according to one theory of self-assembly, the differential adhesion hypothesis (DAH) - first proposed in 1962, the cells aggregate as a spheroid to maximise adhesion and minimise energy. Different cell types self-segregate according to differences in cell-cell adhesion with cells of highest cohesion forming the inner core of the spheroid and those with lower cohesion to the periphery (Steinberg, 1962; Foty and Steinberg, 2005; Dean et al., 2007; Napolitano et al., 2007). Similar physical influences may determine the relative positioning of MSCs and HUVECs in 3D aggregates, although other factors are likely to be involved. Using confocal microscopy and immunohistochemistry, we also identified the formation of a network of primitive, CD31-positive capillarylike structures. Other studies have reported angiogenic activity of endothelial cells when co-cultured with stromal cells in 3D biomaterials, with chemical and electrical intercellular coupling implicated as the underlying mechanisms involved (Fuchs et al., 2007; Unger et al., 2007; Hofmann et al., 2008). Quiescence or slow-cycling is a common feature of niche-resident stem cells. We found that MSC proliferation rates in both HDFa controls and HUVEC co-cultures decreased significantly with time in culture, suggesting a retardation of cycling activity in 3D. Furthermore, HUVECs significantly inhibited MSC proliferation over HDFa controls, with more proliferating cells located at the periphery of the spheroid. These data support the ability of endothelial cells to maintain MSC quiescence in a $3 \mathrm{D}$ cellular context. Compared to $2 \mathrm{D}$ cultures, microenvironmental factors, such as nutrient, oxygen or growth factor gradients, are more accurately represented in the 3D model and are likely to result in the non-uniform distribution of proliferating cells, with the spheroid centre favouring quiescence (Griffith and Swartz, 2006).

This study also clearly demonstrated that endothelial cells enhance the osteogenic differentiation of MSCs, as shown by histochemical staining for alkaline phosphatase. Although the precise role of endothelial cells on osteoblastic differentiation is still unclear, several studies have demonstrated a stimulatory effect of endothelial cells on alkaline phosphatase activity when in direct contact 2D co-cultures (Villars et al., 2000; Kaigler et al., 2005; Guillotin et al., 2008; Grellier et al., 2009a; Hager et al., 2009; Li et al., 2010). Grellier et al. showed that endothelial cells supported osteogenesis of human osteoprogenitor cells, when co-immobilised within alginate micropspheres (Grellier et al., 2009b). Related work found a significant increase in osteogenesis when rat kidney vascular endothelial cells and rat bone marrow MSCs were co-cultured on PLGA scaffolds (Sun et al., 2007). However, our results are not in agreement with Kyriakidou et al. who reported that dynamic co-seeding of osteoblasts and endothelial cells on 3D scaffolds had no significant effect on alkaline phosphatase activity and ECM production (Kyriakidou et al., 2008). However, it should be noted that in the above studies artificial matrix material or scaffolds, as well as mature osteoblasts or animal cells, were used. Here, it was notable that osteogenic cells localised more densely near the spheroid surface, as indicated by the presence of alkaline phosphatasepositive cells, with close proximity to CD31-positive cells. Contrary to these results, Stahl et al. (2004) reported that co-culture spheroids differentiated with a central core of osteoblasts. This difference in osteogenic patterning may arise from the fact that these authors used much smaller $3 \mathrm{D}$ aggregates with only 500 cells per spheroid compared to the 30,000 cells per spheroid used here, which would minimise any mechanical/gradient effect. Findings by Ruiz and Chen confirmed that MSCs at the edge of multicellular aggregates differentiated into the osteogenic lineage, while those in the centre became adipocytic when exposed to a 1:1 mixture of adipogenic and osteogenic induction media. The authors suggested a direct link between multicellular form, stress distributions and spatial patterning of stem cell differentiation (Ruiz and Chen, 2008).

We also demonstrated that, unlike their effects on osteogenesis, HUVECs inhibited adipogenic differentiation when co-cultured with MSCs, compared to co-culture with fibroblasts. Related findings were reported by Rajashekhar et al., who found that endothelial cells restrain the adipogenic differentiation potential of adipose stromal cells when co-cultured in 2D (Rajashekhar et al., 2008). It should be noted that HDFa cells were selected in this study as a non-endothelial cell control, to maintain the same MSC numbers in both HUVEC and HDFa co-cultures, which might otherwise bias the data. However, some of our observations may reflect a stimulatory and or inhibitory effect of HDFa on MSC proliferation and differentiation. Several studies have shown fibroblasts to have similar properties to MSCs. In a recent publication, the authors identified the difficulty of distinguishing between adiposederived MSCs (AD-MSCs) and human adult dermal fibroblasts in vitro - regarding their morphological appearance, phenotypic profile and differentiation potential. Both AD-MSCs and HDFas displayed similar capacity to differentiate into osteogenic, adipogenic and cardiomyogenic cell lineages (Blasi et al., 2011). Similarly, dermal-derived fibroblasts from rodent and human were shown to differentiate along the adipogenic and osteogenic lineages (Lorenz et al., 2008). Though conflicting data do exist (Wagner et al., 2005), these observations suggests that, if anything, HDFa would be expected to differentiate alongside the MSCs in MSC/HDFa co-cultures, increasing the level of osteogenic differentiation detected compared to HUVECs. However, during the complex interactions that take place between heterogeneous cell types, stimulatory or inhibitory signals that are presented to MSCs by cells like fibroblasts cannot be discounted.

Whilst it is clear that endothelial cells have a profound influence on MSC fate in a 3D in vitro microenvironment, the nature of the crosstalk between these two cell types is less defined. Signalling pathways, essential for tissue development and growth, such as BMP and Wnt signalling were evaluated, having been identified as candidates in previous work (Saleh et al., 2011). In this study, we 
demonstrated enhanced activation of canonical Wnt signalling, as detected by nuclear $\beta$-catenin, in $3 \mathrm{D}$ cocultures of HUVECs and MSCs, compared to controls, which was suppressed following Dkk-1 exposure. This finding is supported by a previous report that co-cultivation of adipose stromal cells and endothelial cells in 2D upregulates canonical Wnt signalling genes (Rajashekhar et al., 2008). Due to the role that BMP plays in osteogenesis, we wanted to determine whether the observed increase in alkaline phosphatase activity was induced by BMP signalling in our 3D model. Endothelial cells were found to upregulate BMP signalling in MSCs compared to controls as shown by elevated pSmad 1/5/8 staining with intense expression at the periphery of the spheroids. In addition, we showed that the HUVEC-mediated anti-adipogenic effects could be blocked following Wnt signalling inhibition, allowing restoration of MSC adipogenesis. Whilst further studies are required, these data do suggest that endothelial cell-derived Wnt signalling directed towards MSCs may be responsible for regulating their adipogenic potential.

In this study we used macrovascular cell type, HUVECs, as they are the most commonly used human endothelial cell population in vitro. However, it will be interesting to use a microvascular cell type, which originate from capillaries (Xu et al., 1994) as the signals derived from different cell types might affect MSC activity differently. A study by Lozito et al. found that macro- and microendothelial cell matrix composition differs significantly and in turn influences MSC differentiation in different ways under co-culture conditions (Lozito et al., 2009). In addition, HUVECs are of embryonic origin and may differ from adult-derived endothelial cells (Goldbrunner et al., 2000), so it would be beneficial to study MSCs and endothelial cells from the same tissue/donor source. These data strongly suggest that endothelial cells regulate MSC activity and their differentiation capacity, in a manner dependent on the environmental context, which may facilitate the maintenance of MSC quiescence with niche exit and osteogenic differentiation when exposed to the appropriate stimuli. These observations, combined with evidence of suppressed adipogenic differentiation, suggest that endothelial/MSC co-cultures and appreciation of 3D context may offer therapeutic benefits in bone repair.

\section{Acknowledgements}

The authors thank the staff and patients of Harrogate District Hospital for the provision of bone samples and BBSRC and Smith and Nephew plc for supporting this research.

\section{References}

Arufe MC, De la FA, Fuentes-Boquete I, de Toro FJ, Blanco FJ (2009) Differentiation of synovial CD-105(+) human mesenchymal stem cells into chondrocyte-like cells through spheroid formation. J Cell Biochem 108: 145-155.

Bartosh TJ, Ylostalo JH, Mohammadipoor A, Bazhanov N, Coble K, Claypool K, Lee RH, Choi H, Prockop DJ
(2010) Aggregation of human mesenchymal stromal cells (MSCs) into 3D spheroids enhances their antiinflammatory properties. Proc Natl Acad Sci USA 107: 13724-13729.

Blasi A, Martino C, Balducci L, Saldarelli M, Soleti A, Navone SE, Canzi L, Cristini S, Invernici G, Parati EA, Alessandri G (2011) Dermal fibroblasts display similar phenotypic and differentiation capacity to fat-derived mesenchymal stem cells, but differ in anti-inflammatory and angiogenic potential. Vasc Cell 3: 5.

Carrion B, Huang CP, Ghajar CM, Kachgal S, Kniazeva E, Jeon NL, Putnam AJ (2010) Recreating the perivascular niche ex vivo using a microfluidic approach. Biotechnol Bioeng 107: 1024-1032.

Castrechini NM, Murthi P, Gude NM, Erwich JJHM, Gronthos S, Zannettino A, Brennecke SP, Kalionis B (2010) Mesenchymal stem cells in human placental chorionic villi reside in a vascular Niche. Placenta 31: 203-212.

Crisan M, Yap S, Casteilla L, Chen CW, Corselli M, Park TS, Andriolo G, Sun B, Zheng B, Zhang L, Norotte C, Teng PN, Traas J, Schugar R, Deasy BM, Badylak S, Buhring HJ, Giacobino JP, Lazzari L, Huard J, Peault B (2008a) A perivascular origin for mesenchymal stem cells in multiple human organs. Cell Stem Cell 3: 301-313.

Crisan M, Yap S, Casteilla L, Chen CW, Corselli M, Park TS, Andriolo G, Sun B, Zheng B, Zhang L, Norotte C, Teng PN, Traas J, Schugar R, Deasy BM, Badylak S, Buhring HJ, Giacobino JP, Lazzari L, Huard J, Peault B (2008b) A perivascular origin for mesenchymal stem cells in multiple human organs. Cell Stem Cell 3: 301-313.

Cukierman E, Pankov R, Stevens DR, Yamada KM (2001) Taking cell-matrix adhesions to the third dimension. Science 294: 1708-1712.

Cukierman E, Pankov R, Yamada KM (2002) Cell interactions with three-dimensional matrices. Curr Opin Cell Biol 14: 633-639.

da Silva ML, Caplan AI, Nardi NB (2008) In search of the in vivo identity of mesenchymal stem cells. Stem Cells 26: 2287-2299.

da Silva ML, Chagastelles PC, Nardi NB (2006) Mesenchymal stem cells reside in virtually all post-natal organs and tissues. J Cell Sci 119: 2204-2213.

Dean DM, Napolitano AP, Youssef J, Morgan JR (2007) Rods, tori, and honeycombs: the directed self-assembly of microtissues with prescribed microscale geometries. FASEB J 21: 4005-4012.

Dittmer A, Hohlfeld K, Lützkendorf J, Müller L, Dittmer J (2009) Human mesenchymal stem cells induce E-cadherin degradation in breast carcinoma spheroids by activating ADAM10. Cell Mol Life Sci 66: 3053-3065.

Etheridge SL, Spencer GJ, Heath DJ, Genever PG (2004) Expression profiling and functional analysis of wnt signaling mechanisms in mesenchymal stem cells. Stem Cells 22: 849-860.

Foty RA, Steinberg MS (2005) The differential adhesion hypothesis: a direct evaluation. Dev Biol 278: 255-263.

Frith JE, Thomson B, Genever PG (2010) Dynamic three-dimensional culture methods enhance mesenchymal stem cell properties and increase therapeutic potential. Tissue Eng Part C Methods 16: 735-749. 
Fuchs S, Hofmann A, Kirkpatrick CJ (2007) Microvessel-like structures from outgrowth endothelial cells from human peripheral blood in 2-dimensional and 3-dimensional co-cultures with osteoblastic lineage cells. Tissue Eng 13: 2577-2588.

Goldbrunner RH, Wagner S, Roosen K, Tonn JC (2000) Models for assessment of angiogenesis in gliomas. J Neurooncol 50: 53-62.

Grayson WL, Zhao F, Izadpanah R, Bunnell B, Ma T (2006) Effects of hypoxia on human mesenchymal stem cell expansion and plasticity in $3 \mathrm{D}$ constructs. J Cell Physiol 207: 331-339.

Green JA, Yamada KM (2007) Three-dimensional microenvironments modulate fibroblast signaling responses. Adv Drug Deliv Rev 59: 1293-1298.

Grellier M, Bordenave L, Amedee J (2009a) Cell-tocell communication between osteogenic and endothelial lineages: implications for tissue engineering. Trends Biotechnol 27: 562-571.

Grellier M, Granja PL, Fricain JC, Bidarra SJ, Renard M, Bareille R, Bourget C, Amedee J, Barbosa MA (2009b) The effect of the co-immobilization of human osteoprogenitors and endothelial cells within alginate microspheres on mineralization in a bone defect. Biomaterials 30: 3271-3278.

Griffith LG, Swartz MA (2006) Capturing complex 3D tissue physiology in vitro. Nat Rev Mol Cell Biol 7: 211-224.

Guillotin B, Bareille R, Bourget C, Bordenave L, Amedee J (2008) Interaction between human umbilical vein endothelial cells and human osteoprogenitors triggers pleiotropic effect that may support osteoblastic function. Bone 42: 1080-1091.

Hager S, Lampert FM, Orimo H, Stark GB, Finkenzeller G (2009) Up-regulation of alkaline phosphatase expression in human primary osteoblasts by cocultivation with primary endothelial cells is mediated by p38 mitogenactivated protein kinase-dependent mRNA stabilization. Tissue Eng Part A 15: 3437-3447.

Hofmann A, Ritz U, Verrier S, Eglin D, Alini M, Fuchs S, Kirkpatrick CJ, Rommens PM (2008) The effect of human osteoblasts on proliferation and neo-vessel formation of human umbilical vein endothelial cells in a long-term 3D co-culture on polyurethane scaffolds. Biomaterials 29: 4217-4226.

Hutmacher DW (2010) Biomaterials offer cancer research the third dimension. Nat Mater 9: 90-93.

Kaigler D, Krebsbach PH, West ER, Horger K, Huang YC, Mooney DJ (2005) Endothelial cell modulation of bone marrow stromal cell osteogenic potential. FASEB J 19: 665-667.

Kyriakidou K, Lucarini G, Zizzi A, Salvolini E, Mattioli Belmonte M, Mollica F, Gloria A, Ambrosio L (2008) Dynamic co-seeding of osteoblast and endothelial cells on 3D polycaprolactone scaffolds for enhanced bone tissue engineering. J Bioact Compat Polymers 23: 227-243.

Li H, Daculsi R, Grellier M, Bareille R, Bourget C, Amedee J (2010) Role of neural-cadherin in early osteoblastic differentiation of human bone marrow stromal cells cocultured with human umbilical vein endothelial cells. Am J Physiol Cell Physiol 299: C422-C430.
Lorenz K, Sicker M, Schmelzer E, Rupf T, Salvetter J, Schulz-Siegmund M, Bader A (2008) Multilineage differentiation potential of human dermal skin-derived fibroblasts. Exp Dermatol 17: 925-932.

Lozito TP, Kuo CK, Taboas JM, Tuan RS (2009) Human mesenchymal stem cells express vascular cell phenotypes upon interaction with endothelial cell matrix. J Cell Biochem 107: 714-722.

Lutolf MP, Gilbert PM, Blau HM (2009) Designing materials to direct stem-cell fate. Nature 462: 433-441.

Napolitano AP, Chai P, Dean DM, Morgan JR (2007) Dynamics of the self-assembly of complex cellular aggregates on micromolded nonadhesive hydrogels. Tissue Eng 13: 2087-2094.

Pampaloni F, Reynaud EG, Stelzer EH (2007) The third dimension bridges the gap between cell culture and live tissue. Nat Rev Mol Cell Biol 8: 839-845.

Rajashekhar G, Traktuev DO, Roell WC, Johnstone BH, Merfeld-Clauss S, Van Natta B, Rosen ED, March KL, Clauss M (2008) IFATS collection: Adipose stromal cell differentiation is reduced by endothelial cell contact and paracrine communication: role of canonical Wnt signaling. Stem Cells 26: 2674-2681.

Rangarajan A, Hong SJ, Gifford A, Weinberg RA (2004) Species- and cell type-specific requirements for cellular transformation. Cancer Cell 6: 171-183.

Ruiz SA, Chen CS (2008) Emergence of patterned stem cell differentiation within multicellular structures. Stem Cells 26: 2921-2927.

Saleh FA, Genever PG (2011) Turning round: multipotent stromal cells, a three-dimensional revolution? Cytotherapy 13: 903-912.

Saleh FA, Whyte M, Ashton P, Genever PG (2011) Regulation of mesenchymal stem cell activity by endothelial cells. Stem Cells Dev 20: 391-403.

Shi S, Gronthos S (2003) Perivascular niche of postnatal mesenchymal stem cells in human bone marrow and dental pulp. J Bone Miner Res 18: 696-704.

Stahl A, Wenger A, Weber H, Stark GB, Augustin HG, Finkenzeller G (2004) Bi-directional cell contact-dependent regulation of gene expression between endothelial cells and osteoblasts in a three-dimensional spheroidal coculture model. Biochem Biophys Res Commun 322: 684-692.

Steinberg MS (1962) On the mechanism of tissue reconstruction by dissociated cells. III. Free energy relations and the reorganization of fused, heteronomic tissue fragments. Proc Natl Acad Sci USA 48: 1769-1776.

Sun H, Qu Z, Guo Y, Zang G, Yang B (2007) In vitro and in vivo effects of rat kidney vascular endothelial cells on osteogenesis of rat bone marrow mesenchymal stem cells growing on polylactide-glycoli acid (PLGA) scaffolds. Biomed Eng Online 6: 41.

Tapp H, Deepe R, Ingram J, Kuremsky M, Hanley E, Gruber H (2008) Adipose-derived mesenchymal stem cells from the sand rat: transforming growth factor beta and 3D co-culture with human disc cells stimulate proteoglycan and collagen type I rich extracellular matrix. Arthritis Res Ther 10: R89.

Unger RE, Sartoris A, Peters K, Motta A, Migliaresi C, Kunkel M, Bulnheim U, Rychly J, Kirkpatrick CJ (2007) Tissue-like self-assembly in cocultures of endothelial 
cells and osteoblasts and the formation of microcapillarylike structures on three-dimensional porous biomaterials. Biomaterials 28: 3965-3976.

Villars F, Bordenave L, Bareille R, Amedee J (2000) Effect of human endothelial cells on human bone marrow stromal cell phenotype: role of VEGF? J Cell Biochem 79: 672-685.

Wagner W, Wein F, Seckinger A, Frankhauser M, Wirkner U, Krause U, Blake J, Schwager C, Eckstein V, Ansorge W, Ho AD (2005) Comparative characteristics of mesenchymal stem cells from human bone marrow, adipose tissue, and umbilical cord blood. Exp Hematol 33: 1402-1416.

Wang CC, Chen CH, Hwang SM, Lin WW, Huang CH, Lee WY, Chang Y, Sung HW (2009a) Spherically symmetric mesenchymal stromal cell bodies inherent with endogenous extracellular matrices for cellular cardiomyoplasty. Stem Cells 27: 724-732.

Wang W, Itaka K, Ohba S, Nishiyama N, Chung UI, Yamasaki Y, Kataoka K (2009b) 3D spheroid culture system on micropatterned substrates for improved differentiation efficiency of multipotent mesenchymal stem cells. Biomaterials 30: 2705-2715.

Xu Y, Swerlick RA, Sepp N, Bosse D, Ades EW, Lawley TJ (1994) Characterization of expression and modulation of cell adhesion molecules on an immortalized human dermal microvascular endothelial cell line (HMEC1). J Invest Dermatol 102: 833-837.

Yamada KM, Cukierman E (2007) Modeling tissue morphogenesis and cancer in 3D. Cell 130: 601-610.

\section{Discussion with Reviewers}

Reviewer I: Are the HUVECs the source of BMP and Wnt ligands in the 3D co-culture model with MSCs?

Authors: This is yet to be fully determined. BMP and Wnt signalling were identified as candidates using a bioinformatics-based approach (Saleh et al., 2011, text reference) and we have provided strong circumstantial evidence (increased pSmad and beta-catenin immunostaining). However, a direct interaction using these pathways has not yet been proven and will be the subject of future studies.

Reviewer I: Stem cells can form hybrids. Can the authors exclude occurrence of cell fusion between HUVECs and MSCs in their 3D co-culture model?

Authors: Yes. We find no evidence of cell fusion between HUVECs and MSCs, even under conditions reported to promote it, including exposure to polyethylene glycol, heat shock and low serum, in both 2D and 3D culture.

Reviewer II: You have used a mixture of DMEM and ECGM plus supplements for your co-culture approach. Have you observed similar effects and indications for Wnt and BMP signalling when other cell culture media have been applied in the co-culture?

Authors: We selected the DMEM/ECGM supplemented medium from a range of others based on optimal MSC and HUVEC viability and growth characteristics. We have not tested the effects of different media on signalling activity in co-culture and there may be variations. However, we would suggest that any findings would be compromised by the use sub-optimal growth conditions.

Reviewer III: Some of the results are promising, but most of them are hard to see, therefore difficult to estimate. Most of the results are qualitative. Other methods of evaluation would be beneficial to confirm the results (e.g., for cell proliferation, differentiation, signal transduction). It might be possible to separate the cells from each other using some enzyme digestion of the matrix binding, followed by cell sorting steps (e.g., FACS, magnetic separation), and then do some gene analyses on the two cell populations.

Authors: One of the key aims of the work was to analyse the two cell types in 3D, in situ, without using disruptive or cell sorting techniques. We propose that the 3D model allows the study on cell-cell interactions in an in vivo-like environment that would be lost following separation. This reflects our choice of (non-disruptive) techniques in the assays we used (though admittedly in some cases at the expense of more robust quantification), but we have now included substantial quantification of these analyses and additional experimentation. We agree that further analyses of proliferation/differentiation/signaling are important but beyond the scope of the current work. 